\title{
Describing of Referral Health System for Pregnant Women in Al-Najaf-Iraq
}

\author{
Atheer Kadhim Ibadi* \\ Department of Pharmacy, Kufa Institute, Al-Furat Al-Awsat Technical University, Iraq
}

Received: May 11, 2018; Published: May 17, 2018

*Corresponding author: Atheer Kadhim Ibadi, Department of Pharmacy, Kufa Institute, Al-Furat Al-Awsat Technical University, 31001 Kufa, Al-Najaf, Iraq

\section{Abstract}

Background: The development of actual patient referral systems is considered one of the important public health issues in developing countries. Primary health care services will not be benefit without effective procedures in the hospital that support to refer the patients who need special services. The medical health care system in Iraq based on a hospital oriented and capital-intensive model that has limited efficiency and does not have equitable access.

Objective: This study was conducted to describe the referral health system in Al-Najaf province, Iraq.

Materials and Methods:A cross-sectional study has described the referral health system in Iraq, Al-Najaf province. This study is the first national research has been conducted to describe the referral health system (the pregnant women as an example). The researcher has reviewed a group of studies reported in (Medline, WHO Portal, POPLINE, PubMed) databases that have assessed the referral health system. The medical services for women are provided in an integrated and comprehensive manner covering preventive, promotive and curative aspects of care in a set of phases are (antenatal care, delivery care, postnatal care, family planning and care for the newborn).

Outcomes: The referral system in Iraq is classified to three levels are: PHC main centers which is including three categories of PHC (A-approx. 817 centers delivered all the primary health care services), (B-approx. 19 centers includes the same services as a category (A) plus a training place) and(C- approx. 123 centers includes the same services as Class (A) in addition to emergency care services. Second, PHC Subcenters (called Category D) includes 53 centers deliver simple curative services, immunization activities and simple maternal and child health services. Third, Hospitals: Secondary and tertiary care levels are provided by 208 government hospitals, providing 36057 hospital beds and 80 private hospitals ( 2273 beds).

Conclusion: Decades of war and sanctions have seriously compromised the function of the health system. There are adequate financial resources, but with a shortage of skills, strategies and human resource development. In addition, the health strategies have failed to link needs, strategic plans, and training programs together.

Keyword: Referral Health System; Referral of Pregnant Women

\section{Introduction}

The development of patient referral systems is considered one of the important public health issues in developing countries. Primary health care services will not be benefit without effective procedures in the hospital that support to refer the patients who need special services and to refer patients who do not require hospital care back to one of the other services [1]. Appropriate referral of high-risk pregnancy from traditional birth attendants to public institutions is one of the main aspects of reproductive health programs in the rural areas [2,3]. However, few studies have been undertaken about patient referral systems in developing countries [4-9]. In developed countries, some studies have focused on the type of referral messages and the appropriateness of the referral $[10,11]$.

In Iraq, The health care system has been based on a hospital oriented and capital-intensive model that has limited efficiency and does not have equitable access. The Ministry of Health is the main provider of health care (curative and preventive). The private sector provides curative services only. In addition to that, access to health care has been further affected by years of conflict, sanctions, and ongoing military operations [12]. The Ministry of Health vision in 2004 for primary health care was (available, an accessible, affordable, safe and comprehensive health service 
of the highest possible standard). These services are founded on scientific principles to meet the present and future health needs of Iraqi people. These services established for all regardless of their ethnicity, geographic origin, gender or religious affiliation. Therefore, calls for integrated reform of the existing PHC system [13].

In practice, there is a minimum level of coordination between thePHClevel and the district hospitals apart from communicable disease surveillance. The referral system is either rudimentary or practically non-existent. No system of general or family practice is yet in place. However, family practice has been accepted as a policy and is being piloted in three locations: Basrah, Baghdad, and Mosul. Health center and hospital care are not coordinated within district health systems [14]. In addition, over two decades of war, conflict and prolonged economic sanctions have led to a deterioration in the type of service provision, a shortage of technical expertise, diagnostic services, and a rationing of drugs. This situation has forced patients to seek services at the tertiary care level. Consequently, the majority of people go directly to the hospital. Approximately 65\% of deliveries take place at hospitals. Family planning services are also mainly provided through hospitals (67\%) [15].

\section{Material and Methods}

\section{Study Location}

This study was conducted in Al-Najaf province, one of the eighteen provinces in Iraq. Al-Najaf Province consists of six districts, namely, Najaf, Hydaria, Munathera, Al-Abbasia, Kufa, and AlMishkhab. In $2006 \mathrm{Al}$ Najaf had a population of 1,042,900, which represent $3.7 \%$ of total population in Iraq $[16,17]$.

\section{Study Design and Exclusion Criteria}

A cross-sectional study has described the referral health system in Al-Najaf province, Iraq. This study is the first national research has been conducted to describe the referral health system for the pregnant women. The health of pregnant women and their children are considered the vital group in the community. The researcher was reviewed a group of studies reported in (Medline, WHO Portal, POPLINE, PubMed) databases that have assessed the referral health system. Services for women are provided in an integrated and comprehensive manner covering preventive, promotive and curative aspects of care in a set of phases are(antenatal care, Table 1: Antenatal care services according to health facility levels. delivery care, postnatal care, family planning and care for the newborn).

\section{Ethical}

This study had ethical approval was given by Al-Najaf Health Directorate $\backslash$ Center of Training and Development of Staffs (ref: No. 36830), also written consent was taken from all respondents.

\section{Results}

The Referral System in Iraq is Classified to Three Levels are:

\section{PHC main Centers; There are three Categories of PHC} Main Centers:

i. Primary health care centers (Category: A) - approximately 817 centers, these centers deliver all the primary health care services.

ii. Primary health care training center (Category: B) approximately 19 centers. These centers offer the same services as a category (A) plus a training place within the main building to deliver training activities for medical, paramedical staff of health facilities, medical institutions, and students of medical school.

iii. Primary health care centres with delivery room and emergency unit: (Category: C) - approximately 123 centres. These centres deliver the same services as ClassA facilities in addition to emergency care services (for simple medical and surgical cases) and services for normal labour.

\section{PHC Sub-Centers}

i. Primary health care sub-centers: (Category: D) approximately 53 centers, deliver simple curative services, immunization activities and simple maternal and child health services.

\section{Hospitals}

PHC centers are intended to refer to the second level of care at Ministry of Health district and general hospitals. Secondary and tertiary care is provided by 208 government hospitals, providing 36057 hospital beds and 80 private hospitals (2273 beds). The ratio of beds in public hospitals is 11.3 per 10000 population with a bed occupancy rate of $48 \%$.

\begin{tabular}{|c|c|c|c|c|}
\hline \multirow{2}{*}{ Services } & \multicolumn{4}{|c|}{ Health Facility Levels } \\
\hline & СHH & PHC sub-Center & PHC main Center & District \\
\hline \multicolumn{5}{|c|}{ Antenatal Care } \\
\hline \multicolumn{5}{|l|}{ Information, education and } \\
\hline communication (IEC) & Yes & Yes & Yes & Yes \\
\hline Premarital Examination and counseling & & & Yes & Yes \\
\hline Diagnosis of pregnancy & Assumption & Assumption & Yes & Yes \\
\hline Antenatal visits - weight, height measurement, etc... & & Yes & Yes & Yes \\
\hline Tetanus immunization & & & Yes & Yes \\
\hline Multi-micronutrient supplementation & & Yes & Yes & Yes \\
\hline Blood pressure measurement & & Yes & Yes & Yes \\
\hline
\end{tabular}




\begin{tabular}{|c|c|c|c|c|}
\hline Blood sugar measurement & & & Yes & Yes \\
\hline Urine analysis & & & Yes & Yes \\
\hline Diagnosis of anemia & & & Yes-blood test & Yes-blood test \\
\hline Treatment of anemia & & Yes-iron/folic & $\begin{array}{c}\text { Yes-iron/folic/ } \\
\text { blood (acute } \\
\text { blood loss) }\end{array}$ & $\begin{array}{c}\text { Yes-iron/folic/ } \\
\text { blood (acute } \\
\text { blood loss) }\end{array}$ \\
\hline Treatment of asymptomatic urinary tract infection & & & Yes & Yes \\
\hline Treatment of symptomatic urinary tract infection & & & Yes & Yes \\
\hline Treatment of sexually transmitteddiseases & & & $\begin{array}{l}\text { Yes based on lab } \\
\text { findings }\end{array}$ & $\begin{array}{c}\text { Yes based on lab } \\
\text { findings }\end{array}$ \\
\hline Detection of pregnancy at risk & Yes and refer & Yes and refer & Yes & Yes \\
\hline Treatment of hypertensive disorders of pregnancy & & & Yes if specialist & Yes \\
\hline \multicolumn{5}{|l|}{ Treatment of pre-eclampsia/eclampsia } \\
\hline & & & Yes and early referral & Yes \\
\hline Treatment of incomplete miscarriage/ abortion & & & & Yes \\
\hline Treatment of ectopic pregnancy & & Stabilize and refer & Stabilize and refer & Yes \\
\hline Reporting & & Yes & Yes & Yes \\
\hline Supervision and monitoring & & Yes & Yes & Yes \\
\hline
\end{tabular}

Table 2: Delivery care services according to health facility levels.

\begin{tabular}{|c|c|c|c|c|}
\hline \multirow{2}{*}{ Services } & \multicolumn{4}{|c|}{ Health Facility Levels } \\
\hline & $\mathrm{CHH}$ & PHC sub-Center & PHC main Center & District \\
\hline \multicolumn{5}{|c|}{ Delivery Care } \\
\hline IEC & Yes & Yes & Yes & Yes \\
\hline Monitoring labor & & & & Yes \\
\hline Detection of Fetal Risks & Yes & Yes and refer & Yes & Yes \\
\hline Identify fetal malposition & & & Yes & Yes \\
\hline Assist normal delivery & & & Yes (if category C) & Yes \\
\hline $\begin{array}{c}\text { Delivery requiring assisting } \\
\text { instrumentation }\end{array}$ & & Refer & Yes (if category C) & Yes \\
\hline IV oxytocin refer & & Refer & Yes (if category C) & Yes \\
\hline IV anticonvulsant & & & yes and refer & Yes \\
\hline IV fluids & & & & Yes \\
\hline Blood Transfusion & & & & Yes \\
\hline Curettage & & & yes (if category C) & Yes \\
\hline Hysterectomy & & & & Yes \\
\hline Management of prolapsed cord & & & yes (if category C) & Yes \\
\hline Management of shoulder dystocia & & & yes (if category C) & Yes \\
\hline Vacuum extraction & & & yes (if category C) & Yes \\
\hline External cephalic version & & & yes (if category C) & Yes \\
\hline Caesarian section & & & & Yes \\
\hline
\end{tabular}

Table 3: Postnatal care services according to health facility levels.

\begin{tabular}{|c|c|c|c|c|}
\hline \multirow{2}{*}{ Services } & \multicolumn{5}{|c|}{ Health Facility Levels } \\
\cline { 2 - 5 } & CHH & PHC sub-Center & PHC main Center & District \\
\hline \multicolumn{7}{|c|}{ Postnatal care } & Yes & Yes & Yes \\
\hline IEC & Yes & Yes
\end{tabular}




\begin{tabular}{|c|c|c|c|c|}
\hline Vitamin A supplementation & & Yes & Yes & Yes \\
\hline Detection of anemia & refer suspected cases & refer suspected cases & Yes -Lab & Yes -Lab \\
\hline Treatment of anemia & & Yes & Yes & Yes \\
\hline Diagnosis of puerperal infection & refers suspected cases & Refer & Yes & Yes \\
\hline Breast examination & Yes & Yes & Yes & Yes \\
\hline Prescription of antibiotics & & & Yes & Yes \\
\hline $\begin{array}{c}\text { Counseling on FP and exclusive } \\
\text { breastfeeding }\end{array}$ & Yes & Yes & Yes & Yes \\
\hline Provide Family Planning & Yes-condom & Yes & Yes & Yes \\
\hline Treatment of post-partum psychosis & & & Yes & Yes \\
\hline $\begin{array}{l}\text { Confidential reporting about } \\
\text { maternalMortality }\end{array}$ & & & Yes & Yes \\
\hline Reporting & Yes & Yes & Yes & Yes \\
\hline Supervision and monitoring & & Yes & Yes & Yes \\
\hline
\end{tabular}

Table 4: Family planning services according health facility levels.

\begin{tabular}{|c|c|c|c|c|}
\hline \multirow{2}{*}{ Services } & \multicolumn{4}{|c|}{ Health Facility Levels } \\
\hline & CHH & PHC sub-Center & PHC main Center & District \\
\hline \multicolumn{5}{|c|}{ Family Planning } \\
\hline Counseling & Yes & Yes & Yes & Yes \\
\hline Clinical examination & & & Yes & Yes \\
\hline Screening for STD & Refer & Refer & Yes & Yes \\
\hline Treatment of STD & & & Yes - Oral/IV & Yes - Oral/IV \\
\hline Distribute condoms & Yes & Yes & Yes & Yes \\
\hline Distribute oral contraceptives & Yes & Yes & Yes & Yes \\
\hline IUD & & & Yes & Yes \\
\hline Female sterilization & & & & Yes \\
\hline Male sterilization & & & & Yes \\
\hline Reporting & Yes & Yes & Yes & Yes \\
\hline Supervision and monitoring & & Yes & Yes & Yes \\
\hline
\end{tabular}

Table 1 shows that a set of antenatal care services according to health facility levels. These services are composed of a group of diagnostic, preventive and curative procedures; the pregnant women are considered one of the important groups who attend to these centers. Table 2 shows that a set of delivery care services according to health facility levels. These services contain a group of procedures that give to the pregnant women during childbirth level. Table 3 shows that a set of postnatal care services according to health facility level. These services are composed of a group of diagnostic, preventive and curative procedures; the pregnant women are considered one of the important groups that attend to these centers. Table 4 reveals that the family planning services, these services have given into the pregnant women that have attained to these centers.

\section{Discussion}

From 1970 to 1980, Iraqi health care and medical education were said to be the best in the region. The country boasted free health care in 172 hospitals and 1200 primary health-care clinics. Iraqi medical graduates would often receive specialty training and certification in the UK and Germany. From the late 1980s until 2004, most medical graduates were barred from leaving Iraq [18]. The 1980-88 Iran-Iraq War killed perhaps half a million people on both sides, and further diverted resources and medical staff from civilian facilities [19]. In 1991, Iraq invaded Kuwait, triggering the first Gulf War. The sanctions that followed had a major effect on Iraq's health system and the health status of Iraqis [13]. The subsequent oil-for-food program mitigated some of the effects of sanctions, but serious damage had been done to the health system. At the time of the 2003 US-led invasion of Iraq, the health system was weak, with non-functioning equipment, inadequate drug supplies, and fragile infrastructure [20]. The destruction and looting of health facilities that followed the invasion resulted in heavy loss of equipment and pharmaceutical stocks [21]. The quality of care continued to deteriorate, and shortages were widespread [15]. Major loss of health staff from tertiary hospitals had an effect on teaching of trainees and care of patients [8].

In 2012, the UN High Commissioner for Refugees estimated that 3.1 million people in Iraq were in need of assistance (UNHCR, 2012); about 1.4 million people are internally displaced (IDMC, 2012).Both refugees and internally displaced individuals have 
unsatisfactory access to health services [22,23]. During the 200311 occupation of Iraq by coalition forces, $\$ 53$ billion in assistance schemes were implemented with varying success [24]. The Federal Ministry of Health went through difficult times, under the control of various sectarian groups [25].

\section{Conclusion}

Decades of sanctions and war have seriously compromised the function of health system. There are adequate financial resources, but with a shortage of skills, strategies and human resource development. In addition, the health strategies have failed to link needs, strategic plans, and training programs together. The ideal health policy has seem to emphasize the further development of a health system based on the family health-care model, resources are heavily directed toward expansion of secondary and tertiary healthcare facilities. Finally, the continuing insecurity in Iraq makes even the best plans difficult to implement [26-28].

\section{References}

1. World Health Organization (1987) Hospitals and health for all. Technical Report Series No. 744. Geneva: WHO.

2. Alisjahbana A, Williams C, Dharmayanti R, Hermawan D, Kwast BE, et al. (1995) An integrated village maternity service to improve referral patterns in a rural area in West-Java. International Journal of Gynecology \& Obstetrics 48: S83-S94.

3. O'Rourke K (1995) The effect of hospital staff training on management of obstetrical patients referred by traditional birth attendants. International Journal of Gynecology \& Obstetrics 48: S95-S102.

4. Saraceno B, Terzian E, BARQUERO FM, TOGNONP G (1995) Mental health care in the primary health care setting: a collaborative study in six countries of Central America. Health Policy and Planning 10(2): 133143.

5. Mwabu GM (1989) Referral systems and health care-seeking behavior of patients: an economic analysis. World Development 17(1): 85-91.

6. Thonneau P, XU Q, Toure B (1994) Obstetric transfers and maternal mortality: a study in Conakry, Guinea. Health Policy and Planning 9(1): 81-85.

7. Mahapatra P, Berman P (1995) Resource allocation for public hospitals in Andhra Pradesh, India. Health Policy and Planning 10(1): 29-39.

8. Lachman PI, Stander IA (1990) Patterns of referral to Red Cross War Memorial Children's Hospital, Cape Town. S Afr Med J 78(7): 404-408.

9. Lachman PI, Stander IA (1991) The referral letter--a problem of communication. South African medical journal= Suid-Afrikaansetydskrifvirgeneeskunde 79(2): 98-100.
10. Sweeny B (1994) The referral system. British Medical Journal 309 (6963): 1180-1181.

11. Hull FM, Westerman RF (1986) Referral to medical outpatients department at teaching hospitals in Birmingham and Amsterdam. BMJ 293(6542): 311-314.

12. Al Hilfi TK, Lafta R, Burnham G (2013) Health services in Iraq. The Lancet 381(9870): 939-948.

13. Daponte BO, Garfield R (2000) The effect of economic sanctions on the mortality of Iraqi children prior to the 1991 Persian Gulf War. American Journal of Public Health 90(4): 546-552.

14. Richards LJ, Wall SN (2000) Iraqi medical education under the intellectual embargo. Lancet (London, England) 355(9209): 1093-1094.

15. Shabila NP, Al-Taweel N, Tahir R, Shwani FH, Saleh AM, Al-Hadithi T (2010) Iraqi health system in Kurdistan region: Medical professionals' perspectives on challenges and priorities for improvement. Confl Health $4: 19$.

16. Ibadi AK, Hamedon TR (2016) Sociodemographic characteristics of pregnant women with toxoplasmosis in Al-Najaf-Iraq. Malaysian Journal of Public Health Medicine 16 (3): 1-12.

17. Central Statistical Organization (CSO) (2013) Demographic Statistics. Ministry of Planning, Republic of Iraq.

18. Middle East Health (2012) Iraq report. On the road to recovery.

19. Baylis J, Wirtz JJ,Gray CS (2013) Strategy in the contemporary world. Oxford University Press, UK.

20. Aziz C (2003) Struggling to rebuild Iraq's health-care system. Lancet 362: $1288-1289$.

21. Knapp C (2003) Anarchy pushes Iraqi health system to brink of collapse. Lancet. (London, England), 361:1351.

22. Doocy S, Malik S, Burnham G (2010) Experiences of Iraqi doctors in Jordan during conflict and factors associated with migration. Am J Disaster Med 5: 41-47.

23. URC-CHS (2015) Strategies for improving health services for internally displaced persons in Iraq.

24. Williams T (2010) Report seeks sole agency to rebuild war zones. New York Times, USA.

25. Burnham GM, Lafta R, Doocy S (2009) Doctors leaving 12 tertiary hospitals in Iraq, 2004-2007. Social science \& medicine 69(2): 172-177.

26. Doocy S, Sirois A, Anderson J (2011) Food security and humanitarian assistance among displaced Iraqi populations in Jordan and Syria. Soc Sci Med 72: 273-82.

27. Internal Displacment Monitoring Center (2012) Iraq: response still centered on return despite increasing IDP demands for local integration.

28. UN Refugee Agency (2012) UNCHR Country operations profile-Iraq.
This work is licensed under Creative Commons Attribution 4.0 License

Submission Link: https://biomedres.us/submit-manuscript.php

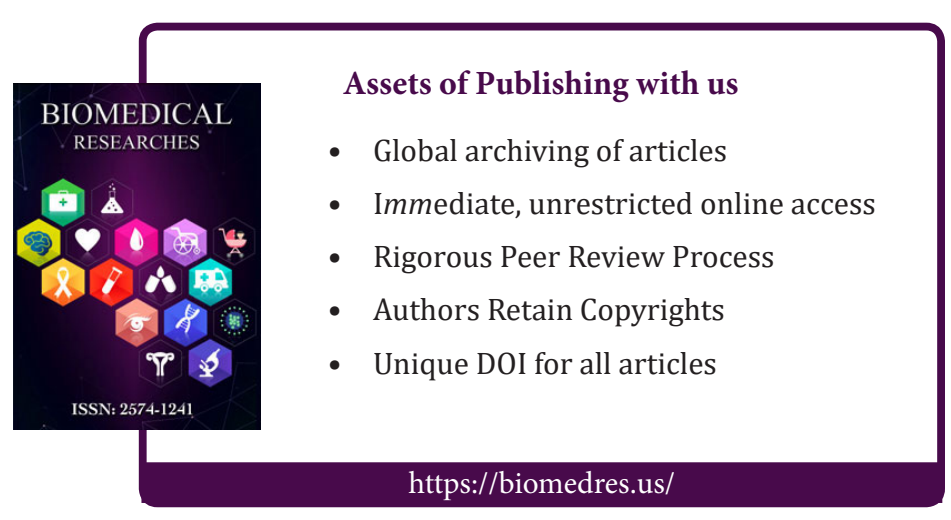

